\title{
HISTORICAL TRENDS IN CRUSTACEAN SYSTEMATICS
}

\author{
BY \\ JOEL W. MARTIN ${ }^{1}$ ) and GEORGE E. DAVIS \\ Research and Collections Branch, Natural History Museum of Los Angeles County, 900 Exposition \\ Boulevard, Los Angeles, CA 90007, U.S.A.
}

\begin{abstract}
Using a database that includes nearly half $(46 \%)$ of the estimated 68,000 described species of extant crustaceans, as well as the names of the authors who described each species and the date of description, we plotted the number of species described vs. year of description to examine rates of, and trends in, crustacean species descriptions over time. Plots were generated for all crustaceans and for selected major taxonomic "subgroups" (currently recognized classes and selected subclasses). The cumulative number of species plotted over time for all crustaceans (pooled) showed no sign of flattening over time; no asymptote was apparent. The same pattern was seen in all subgroups examined (Branchiopoda, Maxillopoda, Copepoda, Malacostraca, Peracarida, Decapoda, and Brachyura). Given that the asymptotes from such analyses have been used to predict species richness in a taxon, our data show that currently there is no reliable way to estimate the number of still-undescribed species of crustaceans through extrapolation. The current estimate of approximately 68,000 described species (Martin \& Davis, 2001; Brusca \& Brusca, 2003) may represent only half, or far fewer, of the actual number of extant crustacean species. No apparent decrease in the overall rate of discovery (approximated by the rate of subsequent taxonomic description) has been observed since the first crustacean species (in our database) were described in the mid-1700s. Over time, the rate of discovery of some smaller taxa, e.g., copepods, did not differ appreciably from the rate of discovery of larger taxa, e.g., brachyuran crabs, based on best-fit regression lines. Although the rates of species accumulations have differed between groups ( 4.6 species per year for branchiopods vs. 82.6 species per year for peracarids), the pace appears steady within groups. The taxonomic contributions of notable workers and their published monographs are highlighted and discussed.
\end{abstract}

\section{RÉSUMÉ}

En utilisant une base de données qui inclut presque la moitié (46\%) des quelque 68000 espèces décrites de crustacés actuels, ainsi que le nom des auteurs qui ont décrit chaque espèce et la date de leur description, nous avons rapporté le nombre d'espèces décrites à l'année de description afin d'examiner les taux des descriptions d'espèces de crustacés par rapport au temps et leurs tendances. Des coordonnées ont été établies pour tous les crustacés et pour quelques sous-groupes taxonomiques majeurs choisis (comme classes et certaines sous-classes reconnues). Le nombre cumulé des espèces

\footnotetext{
1) e-mail: jmartin@nhm.org

(C) Koninklijke Brill NV, Leiden, 2006

Also available online: www.brill.nl/cr
}

Crustaceana 79 (11): 1347-1368 
ainsi rapportée par rapport au temps pour tous les crustacés ne montre pas de signe de baisse avec le temps, aucune asymptote n'est apparente. Le même schéma a été observé dans tous les sousgroupes examinés (Branchiopoda, Maxillopoda, Copepoda, Malacostraca, Peracarida, Decapoda et Brachyura). Etant donné que les asymptotes de telles analyses ont été utilisées pour prédire la richesse spécifique d'un taxon, nos données montrent qu'actuellement, il n'y a pas de moyen fiable d'estimer le nombre d'espèces de crustacés encore non-décrits par une extrapolation. L'estimation présente d'approximativement 68000 espèces décrites (Martin \& Davis, 2001; Brusca \& Brusca, 2003 ) pourrait représenter seulement la moitié, ou beaucoup moins, du nombre actuel d'espèces de crustacés vivants. Aucune diminution apparente du taux de découverte (voisin du taux de description taxonomique) n'a été observée depuis que les premières espèces de crustacés (dans notre base de données) ont été décrites au milieu des années 1700. Au cours du temps, le taux de découverte des taxons les plus petits, comme les copépodes, n'a pas différé notablement du taux de découverte des taxons de plus grande taille, comme les crabes brachyoures, d'après les droites de régression les mieux ajustées. Bien que les taux cumulés d'espèces soient différents suivant les groupes (4,6 espèces par an pour les branchiopodes contre 82,6 espèces par an pour les péracarides), le rythme apparaît constant à l'intérieur des groupes. Les contributions taxonomiques d'auteurs éminents et les monographies qu'ils ont publiées sont citées et discutées.

\section{INTRODUCTION}

A common question concerning biodiversity is how many species exist globally in the various taxonomic groups (Diamond, 1985; May, 1988, 1990; Stork, 1993; Wilson, 2003). Taxonomic names contain data in the form of the name of the author who described the species and the date of the publication of the description. These data can be used to examine historical trends in the numbers and rates of species descriptions (discussed briefly in Köhler et al., 2005). Although discovery of a new species can precede the official description of that species by several years, dates of description can be used as a proxy for dates of discovery to estimate the "rate of discovery" of new species in a given group of organisms.

Current estimates of the number of described crustacean species range from 52,000 (Martin \& Davis, 2001, based primarily on Land, 1996, and Monod \& Laubier, 1996) to 68,000 (Brusca \& Brusca, 2003), with the number of described species increasing each year. Although in recent years some workers have addressed discovery rates within select groups of crustaceans (e.g., Wittmann, 1999, for mysidaceans; Adamowicz \& Purvis, 2005, for branchiopods; Dworschak, 2005, for thalassinidean decapods; De Grave, 2003, for North Atlantic decapods), we are not aware of any attempt to examine such rates in the Crustacea as a whole. Using a database that contains approximately 31,000 crustacean species, or just less than half $(46 \%)$ of the higher estimated total of described species $(68,000)$, we asked the questions: (1) Has the rate of discovery (description) of new species of Crustacea changed appreciably over the years, both for crustaceans as a whole and for individual groups within the Crustacea, and (2) Is there a way to use current data to estimate the number of undescribed species that are yet to be discovered? 


\section{MATERIALS AND METHODS}

For several years, we have been compiling an electronic database containing the names of all extant crustacean species. These species names, including the author and date of description, currently are organized according to the classification proposed by Martin \& Davis (2001). Although there is no consensus among modern crustacean workers as to the "correct" phylogeny and resulting classification of the group, the Martin \& Davis classification is at least a starting point and a framework for organizing our thoughts on crustacean diversity, and it appears to be receiving fairly widespread use (e.g. Brusca \& Brusca, 2003; McLaughlin et al., 2005). Our species list was created by painstakingly entering species names from published monographs and from the primary literature on crustacean systematics. Primary literature consisted mostly of journals such as the "Journal of Crustacean Biology," "Crustaceana," "Proceedings of the Biological Society of Washington," "Smithsonian Contributions in Zoology," and "Zootaxa." Monographic works have included both regional treatments, such as Kensley \& Schotte's (1989) guide to Caribbean isopods, Williams's (1984) guide to east coast decapods, and Poore's (2004) volume on Australian decapods, as well as worldwide treatments of select taxonomic groups, e.g. Holthuis' (1991) volume on lobsters of the world, and Müller's (1994) and Schram \& Müller's (2004) lists of stomatopods. Although we are still slightly less than halfway through (assuming that our estimate of 68,000 described species is accurate) with the task of eventually entering all extant, valid species names of crustaceans, we felt that the approximately 31,000 names currently in our database could be used to estimate historical trends in the descriptions of crustaceans over time. Our database currently includes only two species (the crab Scylla serrata and the barnacle Chelonibia testudinaria) described prior to 1758 , the starting point for the current system of binominal nomenclature in scientific names of species.

The list of 31,000 names contained some "incomplete" entries, where either the author or the date were not included in the source literature. After culling these entries, our total number of species, at the time of submission, was 29,312.

Synonyms are a potential problem in any undertaking that extracts species names from existing literature. Our database is imperfect in that we have not contacted specialists for each of the major crustacean taxa to peruse and correct our lists of names; therefore, the list almost certainly contains some synonyms. However, by beginning our compilation in 1995 and by focusing almost exclusively on modern monographs and syntheses, we have avoided the older literature and thus many of the problems of synonyms. Cursory checks have revealed error rates (synonymies) of only 1 to $3 \%$ in selected groups. Therefore, our working assumption is that the number of errors is probably small enough $(<3 \%)$ that it should be overcome by the sheer volume of the remaining data, such that overriding trends in our 
data should be real. We are also aware that some of the entered names currently in our database belong to fossil taxa, as these were occasionally (accidentally) entered along with names of extant taxa in journals that publish papers on both extant and extinct crustaceans. However, this type of error also is rare in our data (estimated at less than $0.1 \%$ ) and should not affect the overall trends indicated by the more than 29,000 valid names. It is probable that our database is biased toward decapods, as this group is the primary research focus of the first author.

Data were first entered into a Microsoft Access $^{\odot}$ database and were later transferred to a Microsoft Excel $^{\odot}$ spreadsheet in order to remove any incomplete entries and construct the plots. Plots are simple line graphs of the cumulative number of species described over time and were constructed using the "chart wizard" option in Excel. Best-fit regression lines were computed for all graphs to allow comparisons (slope) of the graphs among crustacean groups. Because slope is defined as the change in $Y$ over the change in $X$, the slope in this case is the number of species described over a set period of time (one year); thus, slope is an indicator of the number of species described per year in a given taxonomic group. Once the graphs were completed, we searched the database for underlying reasons, e.g., research expeditions or monographs containing large numbers of described species, that might explain peaks or outlying data points.

\section{RESULTS}

$$
\text { All crustaceans ( } \mathrm{N}=29,312) \text { (fig. 1) }
$$

According to our data, after a relatively slow start in the late 1700s (our database includes only 17 crustacean species names in 1785, and only 3 in 1786, for example), the rate of discovery gradually rose in the early 1800 s until it reached a rate of approximately 100 species per year in the late 1800 s. The rate of discovery steadily increased until it averaged more than 225 species per year in the years 1906 through 1908. There was an appreciable slowing that began approximately in 1916, with descriptions added at a relatively slow rate (for example, only 54 species were named in 1928) until approximately 1960, at which time the rate increased again and at times even surpassed the rate seen in the early part of the century. By 1965 the rate of new species descriptions exceeded 300 per year (315 species were described in 1965). Averaged over the entire range of dates (1755 through 2005), the number of described crustacean species is slightly more than 108 per year. However, if averaged from the year 1850 (a time when, according to the graph, the description rate began to increase) through 2005, the number of described species rises to 164 per year. Although our database, and therefore our graph, reflects only approximately half of the known species, we believe these trends are real, as they 


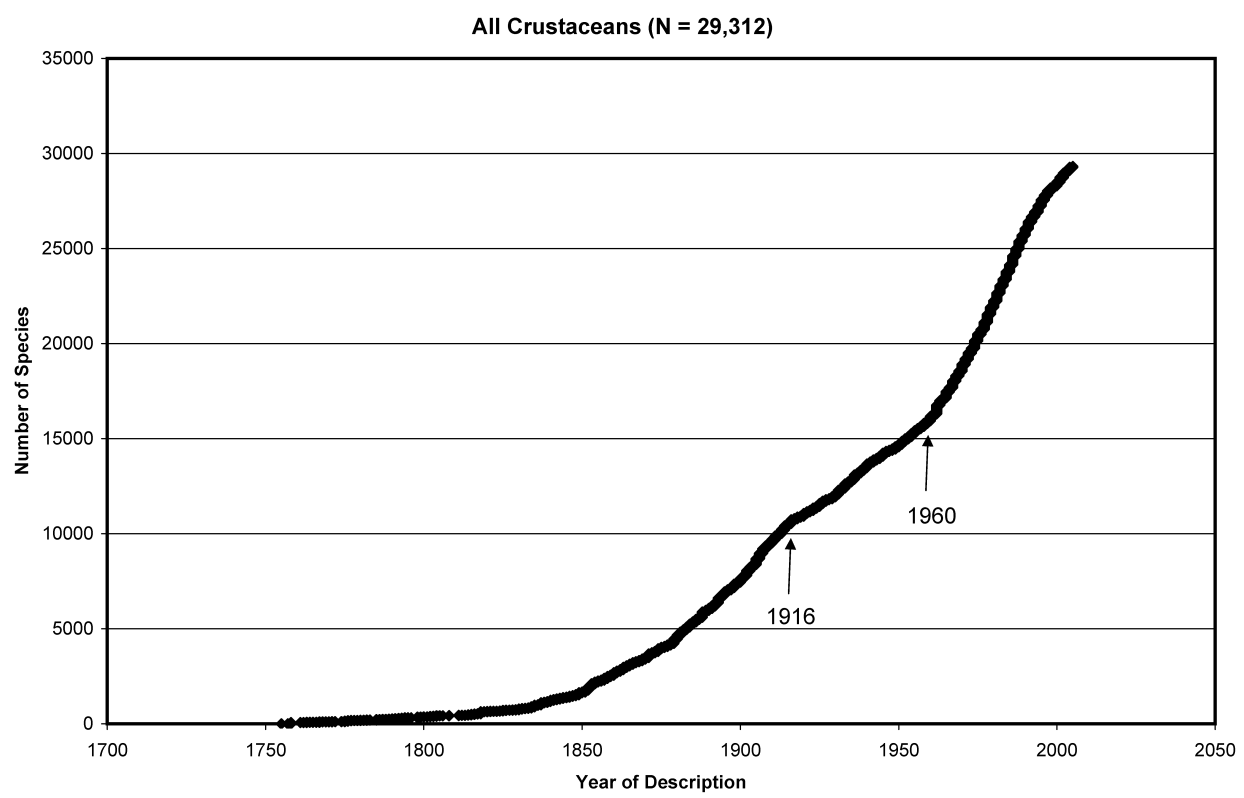

Fig. 1. Cumulative number of species discovered (described) over time for all crustaceans.

TABLE I

Slope and R-squared values for regression lines for all plots of described species within groups of Crustacea

\begin{tabular}{lcc}
\hline & Slope of regression & R squared \\
\hline All Crustacea & 159.69 & 0.93 \\
Branchiopoda & 4.62 & 0.96 \\
Maxillopoda & 25.64 & 0.95 \\
Copepoda & 19.72 & 0.96 \\
Malacostraca & 119.48 & 0.93 \\
Peracarida & 82.62 & 0.88 \\
Decapoda & 39.93 & 0.97 \\
Brachyura & 16.86 & 0.98 \\
\hline
\end{tabular}

are evident to some degree in all subgroups of crustaceans as well as in our pooled data and resulting graphs (see below). A best-fit regression line for all crustaceans exhibits a slope of 159.69 descriptions per year (table I).

$$
\text { Branchiopoda ( } \mathrm{N}=839) \text { (fig. 2) }
$$

Branchiopods are a relatively small class of crustaceans with only some 850 described species (Martin, 1992; Martin \& Davis, 2001; but see Adamowicz \& Purvis, 2005, and our Discussion section for higher estimates). They also tend to occur in small ephemeral bodies of fresh water (pools and streams). Thus, the 


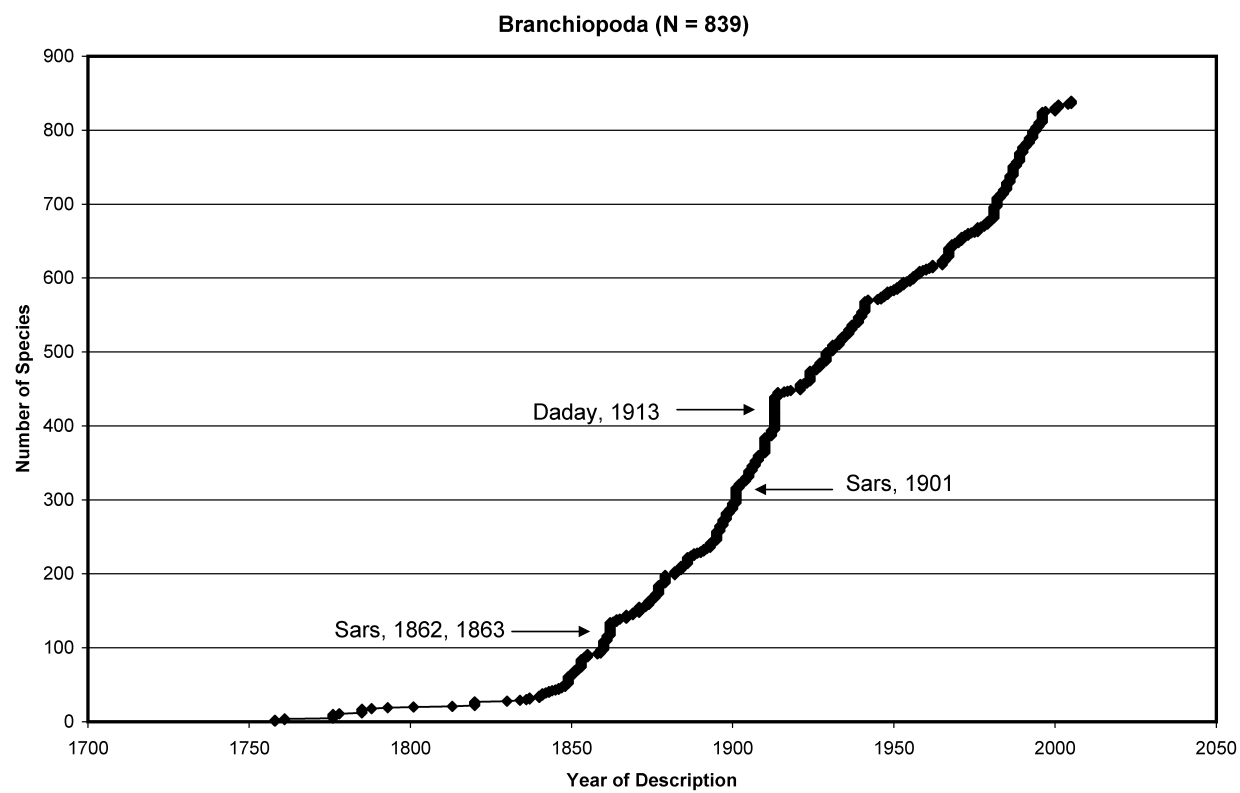

Fig. 2. Cumulative number of species discovered (described) over time for all branchiopod crustaceans.

chances of branchiopods being discovered (and subsequently named) by aquatic as well as terrestrial naturalists are far greater than the chances of similarly-sized marine species of crustaceans being discovered. Because of human encroachment and development, it is also somewhat less likely that large numbers of species have escaped notice (although species continue to be described each year), at least compared to marine crustaceans. Additionally, as is probably true for all crustaceans, branchiopods are a group that was once thought to contain relatively few species that were ubiquitous, a view that is gradually giving way to the realization that many of these "widespread" genera and species contain much previously undetected endemism; morphological similarity has to some extent obscured our knowledge of the group's true diversity (e.g., see Adamowicz \& Purvis, 2005). These factors, plus the fact that branchiopods can be divided and tabulated according to the continents on which they occur, allowed Adamowicz \& Purvis (2005) to employ "correction factors" to arrive at a global estimate of branchiopod species. However, our species accumulation curve (fig. 2) shows that no asymptote was reached in the accumulation of species; therefore, there has been no slowing in our rate of discovery of branchiopods since the early $1800 \mathrm{~s}$. An essentially identical curve was shown by Adamowicz \& Purvis (2005; their fig. 1a), despite the fact that their database contained some 1,180 branchiopod species names. 
The relatively low number of species in our branchiopod database (compared to other groups of crustaceans) makes obvious the relative contributions of such workers as G. O. Sars (Sars, 1862a, b, 1863, 1901) and Eugène Daday (1910, 1913a-c, 1914), the latter of whom described more than 140 species, roughly $1 / 6$ of all currently recognized species in the class, in a single year (Daday, 1913). A best-fit regression line for branchiopods exhibits a slope of 4.62 species per year (table I).

$$
\text { Maxillopoda }(\mathrm{N}=4,388) \text { (fig. 3) }
$$

"Maxillopodans" are generally recognized by most workers today as being an artificial (para- or polyphyletic) assemblage. The group contains (according to the Martin \& Davis, 2001, classification) the well-known and ubiquitous barnacles and copepods as well as many of the smaller and somewhat obscure taxa, e.g. mystacocarids and some of the parasitic thecostracan groups. Ostracodes are sometimes included in this group as well (though not by Martin \& Davis, 2001, and not in the present analysis). Descriptions of maxillopodans began somewhat slowly, reaching a rate of 40 to 50 per year in the mid-1800s, but with a lot of variation between years. The year 1849 saw 57 new descriptions of maxillopods, yet there were only 2 new species described in 1850 (in our database) and 8 described in 1852; in 1854 there were 81 new species added,

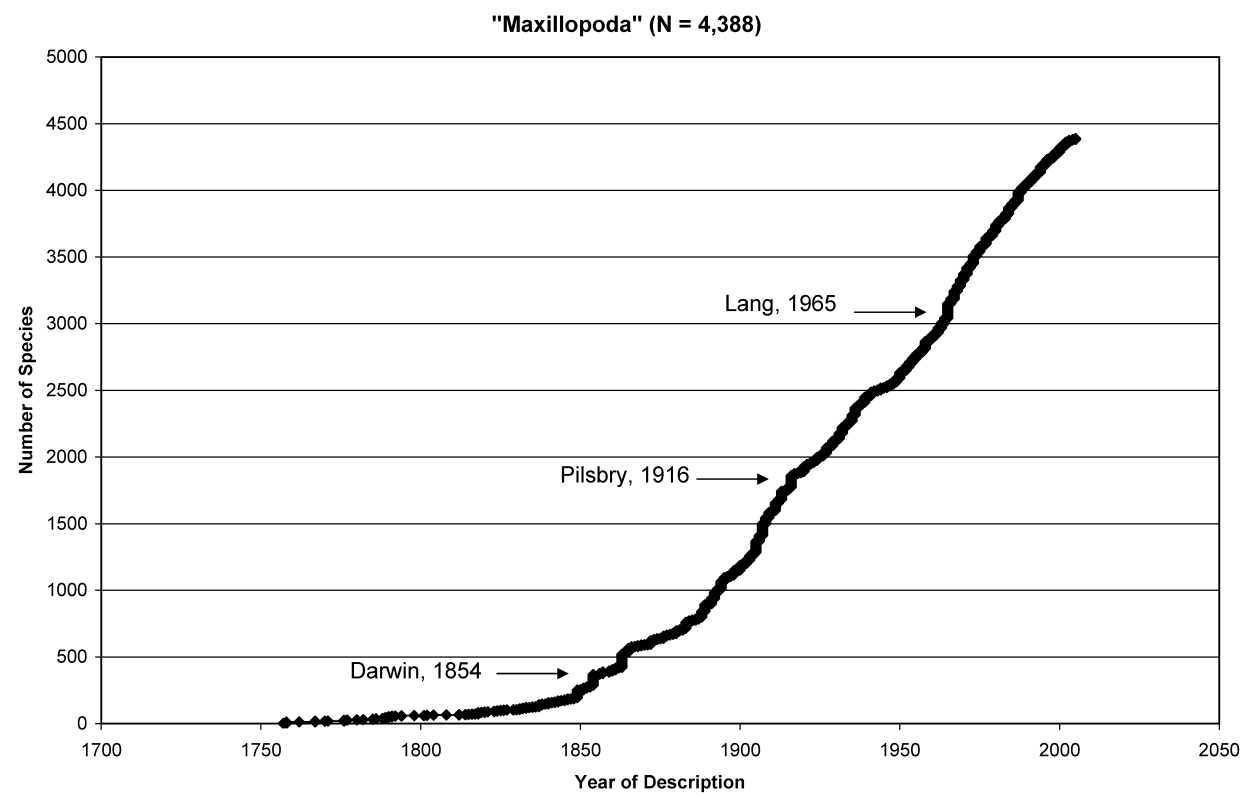

Fig. 3. Cumulative number of species discovered (described) over time for all "maxillopodan" crustaceans (excepting ostracodes). 
mostly as a result of Charles Darwin's work on balanomorph barnacles; Pilsbry's later (1916) contributions to barnacle systematics also are obvious. From the mid-1800s through to today, the rate has remained relatively constant, averaging approximately 30 species per year (again, our data are incomplete and are probably weighted toward non-maxillopodan taxa, so these figures should be considered trends rather than absolutes). Exceptions include the year 1965, when Lang's (1965) descriptions of harpacticoid copepods are notable (see below). A best-fit regression line for all maxillopodans exhibits a slope of 25.64 species per year (table I).

$$
\text { Copepoda }(\mathrm{N}=3,212) \text { (fig. } 4)
$$

Most of the maxillopodans in our database (above) are copepods (roughly 3,200 out of 4,400). We treated copepods separately because they tend to be very small, ubiquitous, and frequently encountered, a recipe that would seem to promise a high rate of discovery of new species. To some extent this is true, i.e., there is certainly no indication that we are nearing the goal of describing all copepods, but no more so than for other groups of crustaceans. After a rather slow start in the late 1700s and early 1800s during which time there were periods of very low activity (we have no descriptions between 1804 and 1816, for example), descriptions of copepod species increased to a rate of approximately 45 species per year in the early 1900s ( 80 species in 1905; 34 in 1906, 18 in 1907; 43 in 1908). A slowdown

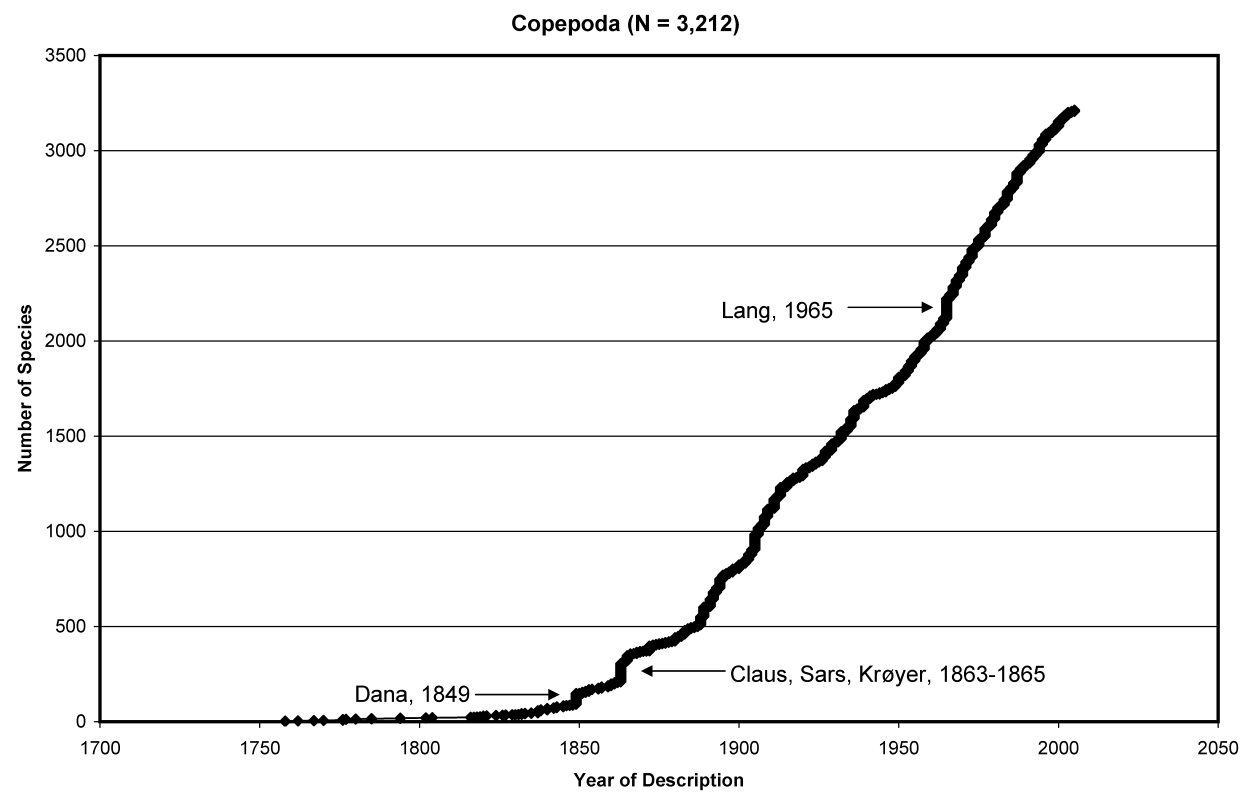

Fig. 4. Cumulative number of species discovered (described) over time for the copepods. 
in the mid-1940s (only 12 species total were described during the years 1943-1945) might reflect the impact of World War II. Obvious advances in our knowledge of copepod taxonomy have come from the contributions of J. D. Dana (1849), three workers (Claus, Sars, and Krøyer) during the years 1863-1865, e.g. Claus (1863a, b) and Krøyer (1863), and the impressive work of Lang (1965), wherein 87 new species were described. A best-fit regression line for copepods exhibits a slope of 19.72 species per year (table I).

\section{Malacostraca $(\mathrm{N}=22,337)$ (fig. 5)}

The Malacostraca include the majority of described crustacean species, as this group contains not only the commercially and economically important decapods but also the incredibly diverse peracarid taxa (amphipods, isopods, tanaids, and others). Fully two thirds of our data (more than 22,000 records) are malacostracans. Not surprisingly, trends in the malacostracan species discovery graph (fig. 5) almost exactly reflect those seen and discussed above under "All crustaceans." A best-fit regression line for the Malacostraca exhibits a slope of 119.48 species per year (table I).

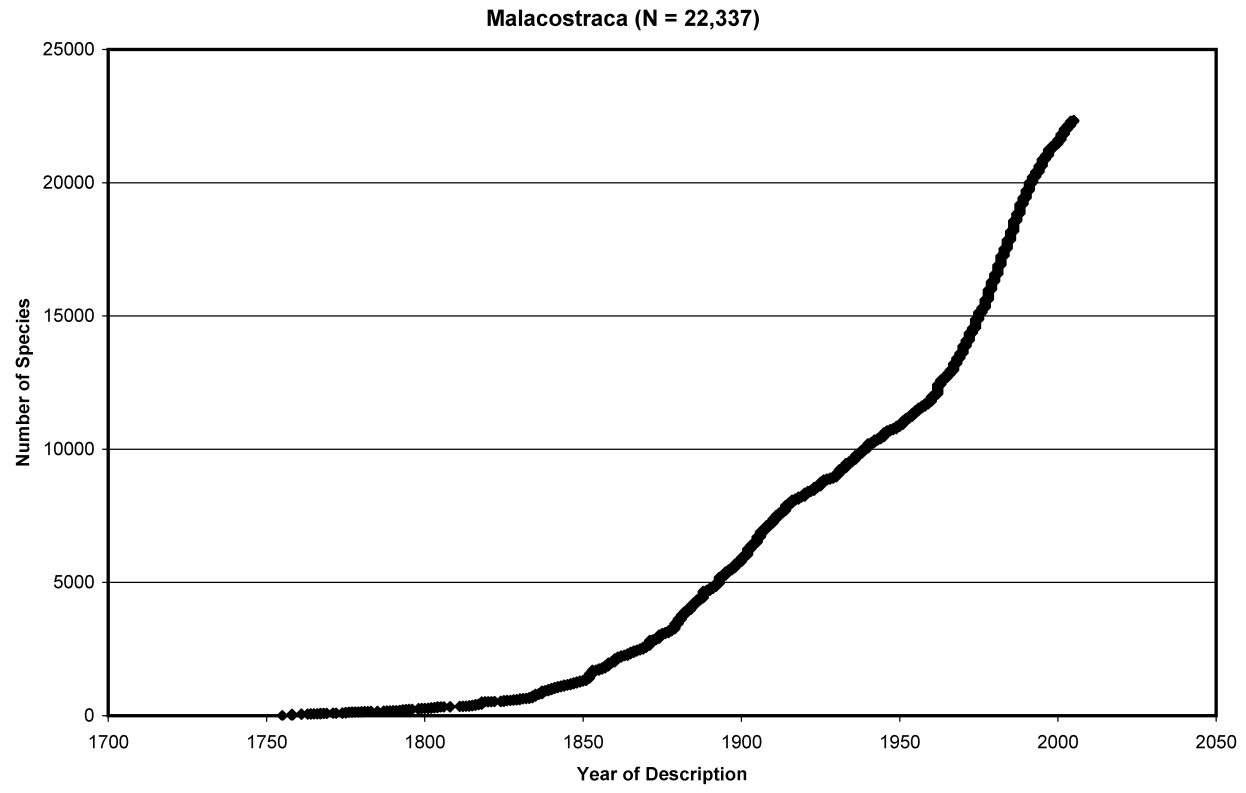

Fig. 5. Cumulative number of species discovered (described) over time for all malacostracan crustaceans. 


$$
\text { Peracarida }(\mathrm{N}=13,797) \text { (fig. 6) }
$$

Peracarid crustaceans (including the amphipods, isopods, tanaidaceans, and others) are a fascinating and diverse assemblage. Species tend to be small (at least smaller than decapods and the large branchiopod groups) but are at least larger than copepods and of a "convenient" size for taxonomy. The group has also attracted the attention of some of carcinology's most prolific workers over the years and is still very popular (in terms of the number of active, practicing carcinologists) today compared to many other crustacean groups (see Martin \& Davis, 2001). These factors might suggest that the group is well known from a taxonomic standpoint. However, such is not the case, in part because the group is also incredibly diverse. By one estimate (Kensley, 1998) there may be more than 54,000 peracarid species associated with coral reefs alone (see also Martin \& Davis, 2001). Peracarids account for more than a third of all species in our database (more than 11,000 of the approximately 30,000 names), and, like the Malacostraca as a whole, exhibit the same general trends seen in the "All Crustacea" graph. A period of slower activity from approximately 1916 through to about 1960 is evident, followed by a peak in the early 1960s attributable mostly to the work of Barnard (for example, our database contains 66 species named by Barnard in 1962), Menzies (122 species in 1962a, b), and several others. Highest rates of discovery are seen in the mid1970s through mid-1980s (on average, 196 species per year were described from

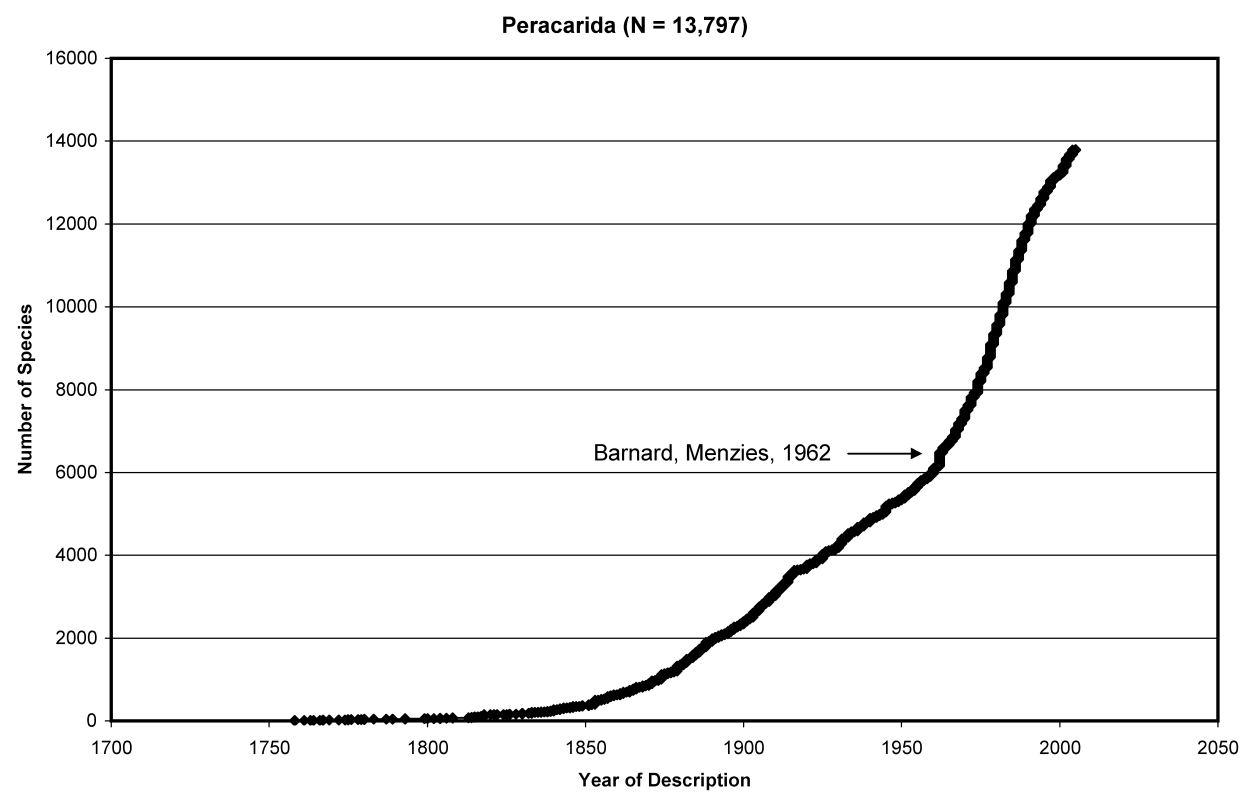

Fig. 6. Cumulative number of species discovered (described) over time for all peracarid crustaceans. 
1975 through 1985). A best-fit regression line for the peracarids exhibits a slope of 82.62 species per year (table I).

$$
\text { Decapoda }(\mathrm{N}=7,905) \text { (fig. 7) }
$$

Decapods are by far the best known and most "important" group of crustaceans from a commercial, economical, and ecological standpoint. They are also the largest crustaceans, including species such as the giant Japanese spider crab, the giant Tasmanian crab, the Maine or American lobster, and other large species. A reasonable assumption might be that these large and commercially important species would be better known as a group much earlier than would smaller crustacean taxa (see De Grave, 2003), such that we might expect to see most species described early on, with fewer new species being described in recent years. A look at fig. 7 shows that this expectation is false. Decapods have been, and continue to be, discovered and described at a rate that is nearly twice the rate of description of new copepods (and approximately half the rate of peracarids) (table I). The rate of decapod discovery has remained fairly constant over time; the number of descriptions in the mid-1800s (58 species were described in 1851) and early 1900s (another 58 species were described in 1901) was not too different from the mid-1990s (where 78 species were described in 1995). There are, as in all groups, outlying points, e.g., 163 species added in 1902), but the overall shape of the species discovery curve (its lack of any discernable asymptote) is similar to

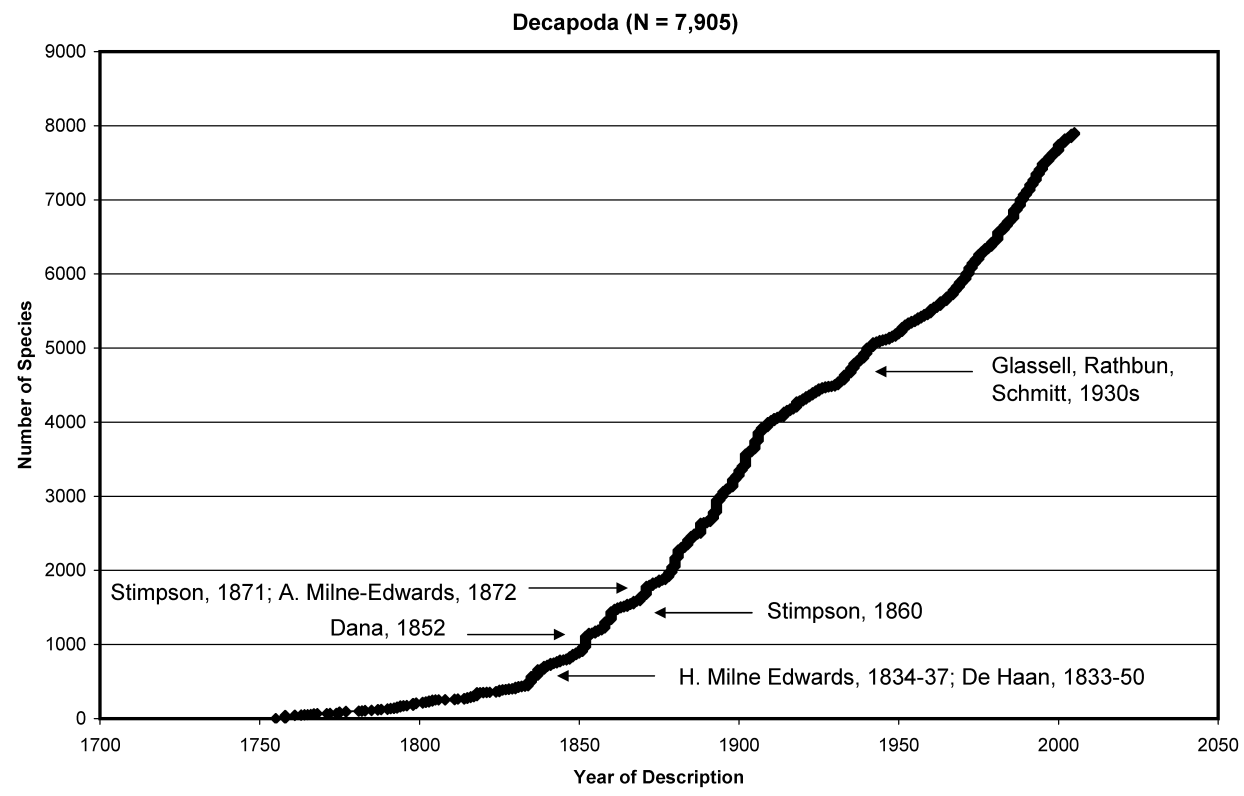

Fig. 7. Cumulative number of species discovered (described) over time for all decapod crustaceans. 
what is seen in other groups. Notable contributions by decapod workers (indicated on the graph) include the works of H. Milne Edwards (1834-1837) and De Haan (1833-1850), Dana (1852), Stimpson (1860, 1871a, b), A. Milne-Edwards (1872, 1880a-c), and of S. Glassell, M. Rathbun, and W. Schmitt in the 1930s (including Glassell, 1935, 1938; Rathbun, 1925, 1930, 1933, 1937; Schmitt, 1935). A best-fit regression line for the Decapoda exhibits a slope of 39.93 species per year (table I).

$$
\text { Brachyura }(\mathrm{N}=3,452) \text { (fig. 8) }
$$

Crabs (brachyurans) were treated separately because of their large size. On average, although there are some very small species of crabs, most crab species attain sizes that exceed those of peracarid and maxillopod crustaceans and sometimes even those of other decapods (with the exception of some lobsters and some anomurans). They are also a more "popular" group than are many other groups of crustaceans, as evidenced by their appearance in popular music and the entertainment industry. We thought it probable that, because of their larger average size, popularity, and economic importance, crabs were more likely to have been discovered and named earlier than would be the case for smaller species of less commercial interest. Fig. 8 shows that this assumption is without merit. Crabs continue to be discovered at rates similar to those of other crustacean groups. The line is less

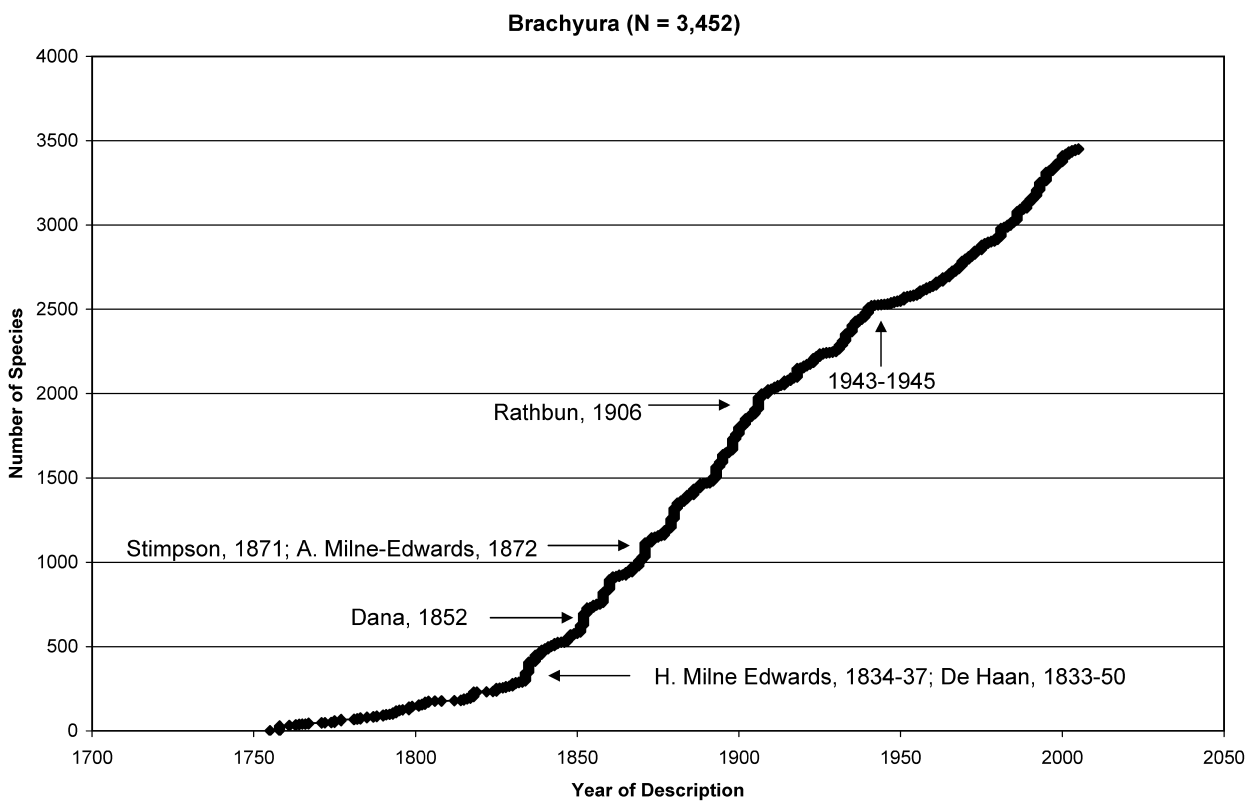

Fig. 8. Cumulative number of species discovered (described) over time for all brachyurans (true crabs). 
"smooth" than in some of the other taxa, meaning that advances in crab taxonomy proceeded in stops and starts, with a few obvious growth spurts in the years 1835-1837, 1853, 1862, 1874, and 1934-1942. However, the overall species accumulation curve is much the same as for decapods as a whole. Major contributors to our knowledge of crab taxonomy are much the same as for all decapods, e.g., De Haan, H. Milne Edwards, A. Milne-Edwards, and Rathbun; see above. Rathbun's (1906) contribution to brachyuran systematics is more obvious in this graph than in the overall decapod graph. There is a near cessation of work on crab systematics during World War II (1943-1945), which for some reason is not reflected as strongly in other groups of crustaceans. A best-fit regression line for brachyuran crabs exhibits a slope of 16.86 species per year (table I).

\section{DISCUSSION}

It is important to note that our database is quite incomplete (containing only approximately half of the estimated number of described crustacean species) and is also biased, not only toward the decapods (the primary research focus of the first author) but toward western journals and literature, which have been our main (though far from our only) source of information. Thus, our findings, as well as the following discussion, must be viewed with these limitations in mind, and our results must be viewed as premature at best. Nevertheless, we believe that the number of species in our database is sufficiently high, and the number of potential errors (such as synonymies) sufficiently low, that the trends shown here will eventually prove to be "real" at whatever point in the future that all or most species are treated this way again. With the number of searchable on-line databases for crustaceans growing each year, it should not be long before this test is possible.

There are some interesting trends in the history of the discovery of new crustacean species based on our limited analysis. First and foremost is the relatively constant rate of species descriptions within groups and the fact that none of the graphs show any signs of "flattening" toward an asymptote over the years, not for crustaceans as a whole nor for any of the subgroups. No asymptote is seen in any of the graphs, although an argument could be made that the slight flattening of the curve in recent years in some taxa is a sign of an approaching asymptote and not, as we suspect, an artifact (see below). Thus, with no clear asymptote, there is no reliable way to estimate whether the current estimate of 68,000 described species represents half, or one third, or even far less of the actual number of extant crustacean species. Although for selected groups it may be possible to insert estimated "correction factors" to account for differences in sampling and taxonomic effort, as was done recently to estimate global branchiopod diversity by 
Adamowicz \& Purvis (2005), such methods have not been applied, nor are they really applicable, to marine groups.

There was a slight decrease in the rate of descriptions evident in nearly all graphs beginning in approximately 1916. It is possible, although we are speculating here, that this decrease reflects a slowing of carcinological research as the world reacted to World War I. Another possibility is that the 1915-1917 slow down reflected a reaction to the great influenza epidemic that began at approximately the same time, during which it is estimated that 50 million people died from the "Spanish Flu" or "La Grippe" worldwide; an estimated $1 / 5$ of the entire world population was infected. But the timing is not quite right for this explanation, as the start of the great flu epidemic is generally attributed to the fall of 1918 (Crosby, 1989; Billings, 1997), at which point the slight decline in the rate of species discovery was already underway. The effect of World War II is also obvious, more so within some groups, e.g., the Brachyura, where descriptions nearly ceased during the years 1943-1945, than for others (e.g., Peracarida). For the Brachyura, our database contains only two crab species described during each of the years 1942 through 1944, and only one species in 1945. For the same period (1942-1945) there were more than 260 species of peracarids described (according to our database). These ratios may change as additional species are added to the database.

Another slight drop in the apparent rate of discovery of new species, one that might at first inspection suggest an approaching asymptote, is seen in nearly all groups in very recent years (beginning in the late 1990s). We attribute this drop to the delay in accumulating species descriptions that have been published in disparate journals over the most recent five to ten years. Species described in the more distant past are more likely to be included in published monographs and regional species lists that are readily available to us, whereas more recently described species, some of which are published in obscure journals that are not included in databases, sometimes are not known to us for several years after their description. In other words, we expect that there will always be an apparent (though artificial) decrease in the rate of discovery seen in recent years as long as we continue to enter data in this manner. Supporting this hypothesis is the fact that similar graphs for taxa for which the data are "complete" (full and accurate species lists from specific geographic locations, for example) show no such flattening in recent years (G. Rosenberg, pers. comm., referring to his databases for mollusks from several geographically circumscribed regions). On the other hand, because only about half of the described species are currently in our database, it is entirely possible that this flattening is "real" - that is, it is possible that we are seeing the beginnings of an asymptote in these groups - and/or that the missing data will drastically alter the shape of the curves. 
Perhaps most surprising to us was the fact that the species description curves for large decapods (all decapods, fig. 7, and crabs by themselves, fig. 8) did not differ appreciably from species curves for smaller, incredibly diverse, and less "important" (from a commercial standpoint) groups such as copepods or peracarids (but see De Grave, 2003, for decapods in the North Atlantic). The slope of the regression line (which in our case approximates the number of new species described per year) is about 17 for crabs, our largest and arguably best known crustaceans, but only 19 for the much smaller and more diverse copepods, and in neither taxon is an asymptote evident. Thus, the assumption that most new species being described today are either small or cryptic (or both), as voiced occasionally by persons assuming that we are almost through with the discovery phase of basic science (Horgan, 1996), is clearly without foundation.

A comparison of our findings with similar approaches that have employed smaller assemblages of crustaceans reveals that the overall shape of the species accumulation curves is much the same. Wittmann's (1999, fig. 1A) graph of the number of mysidaceans (mysids and lophogastrids combined), based on 1026 species and 52 subspecies, shows a slow start in the mid 1700s followed by a relatively constant rate of discovery beginning around 1850 and continuing today (although, interestingly, this is not true for pelagic species, which saw much higher rates of discovery in the early 1900s). For mysidaceans, an increase in the rate of discovery similar to what we described above is seen beginning around 1950, slightly ahead of the same upward trend we noted for all crustaceans beginning around 1960. The reduction in discovery rates that we noted for the years 19161918 is not evident for mysidaceans, although Wittmann's (1999) graph was constructed using 10-year intervals and so might have missed this fluctuation. Adamowicz \& Purvis (2005) and Dworschak (2000, 2005) presented similar graphs for branchiopods and thalassinideans (respectively), two very different groups of crustaceans whose habitats could not be more different (ephemeral freshwater for most branchiopods vs. burrowing marine for most thalassinideans). Dworschak (2005: 59) noted the same general increase in discovery rate in the 1960s, noting that "from that time [1960] on, species numbers again increased rapidly, doubling within 30 years and also continued after 1998." However, Dworschak's (2005) graph differs from ours in the very rapid rate of discovery of new thalassinideans seen in the years 1901-1906, based in part on descriptions of new species resulting from the "Siboga" Expedition (Dworschak, 2005: 59). Adamowicz \& Purvis's (2005, fig. 1a) graph for branchiopods is, not surprisingly, essentially identical to our own graph for that taxon (our fig. 2). Although we have not canvassed the literature for similar treatments of other taxa, these species discovery curves in general agree with other studies on taxa as diverse as trichopteran insects (e.g., Johanson, 1995) and marine mollusks (Bouchet, 1997). 
Can we extrapolate, or estimate, the number of undescribed species based on our data? Because no asymptote is obvious in any of our graphs (with the possible exception noted above for the slight dip in discovery rates seen in recent years), it seems impossible, or at best premature, to do so. Dworschak $(2000,2005)$ felt that "this type of census approach is not suitable to predict actual species number" (Dworschak, 2005: 61). Similarly, Wittmann (1999), discussing mysidaceans, noted that "no extrapolation for the total number of living species seems possible; suffice to say that the final number will be large when compared with the actual one." Yet Wittmann (1999) did extrapolate, extending discovery rates from better studied regions of the globe to other areas, and concluded that the global diversity of all mysidaceans might be "a minimum of 4000 living species," or approximately 4 times the number of currently described species. Adamowicz \& Purvis (2005), studying extant branchiopods, employed similar reasoning to estimate that the number of extant branchiopods might be 2.1 times the current described number. There is some reason to think that their overall estimate of described branchiopod species might be too high. For example, they based the number of living clam shrimp species in part on a checklist by Brtek (1997), who unfortunately made several errors, including the listing of all known species of Eocyzicus as valid under that genus and also under the genus Cyzicus (C. Rogers, pers. comm.); this might in part explain their estimate of 1076 valid species (compared to our estimate of only approximately 850 species). Nevertheless, their estimate of the total number of species cannot be too far off (indeed, we now suspect it is probably closer than our own estimate of 850 species), and their reasons and methods for extrapolation (including comparing well-studied regions to lesser known regions, as did Wittmann, 1999, above) seem reasonable to us. We do not doubt that the number of extant branchiopods is at least 2.1 times the number of described forms. If we assume that the extrapolation figures or "correction factors" given by Wittmann (1999) for mysidaceans (a factor of roughly 4) and by Adamowicz \& Purvis (2005) for branchiopods (a factor of 2.1) apply equally to all crustaceans and there is of course no guarantee that they do - then a conservative estimate for the total number of undescribed crustaceans might be somewhere between these two extrapolation numbers, or $(4+2.1) / 2=$ approximately 3 times the number of described species. This would equal roughly 204,000 extant species of crustaceans. Regardless of such speculations, the salient trend apparent in all of these studies is that the rate of discovery of new crustaceans has not slowed appreciably over time.

One might logically ask how, if the number of taxonomists is on the decline - a cry often voiced by today's systematists - can it be that the rate of discovery of new species has continued unabated? There are several possible explanations, though all of them represent conjecture on our part. First, new information technologies have made it somewhat easier to describe new species 
today compared to what was needed in the past. Background literature searches via the web and the availability of on-line taxonomic databases certainly have the potential to reduce the dependence on the taxonomic libraries and (often unpublished) species lists of specialists. On the other hand, descriptions today tend to be more detailed than the brief descriptions of earlier years. Second, molecular systematic methods are increasingly used to show that former "forms" or "varieties" are deserving of species status, though we hasten to add that this recognition does not by itself constitute a species description, such that taxonomic expertise is still required to provide an adequate description. Thus, to some extent, a decrease in the number of systematists might be offset by an improvement in the methods available to them. The advent of new analytical and molecular genetic tools has been used to explain why descriptions of species in other groups of organisms also are on the rise (see Köhler et al., 2005, for amphibians; Adamowicz \& Purvis, 2005, for branchiopods). Third, as monographs are completed on some taxonomic groups, it becomes easier to focus attention on those groups still in need of serious systematic work. Although seemingly paradoxical, it is actually easier to determine the novelty of a discovery when you are surrounded by accurate monographs of the known fauna than when you do not have such works to assist you and when hardly any species have been described. As we expand the realm of what is known, we highlight what is not known, making it somewhat easier to identify the gaps in our knowledge. At the same time, it becomes more difficult for a carcinologist trained in only one school of thought - morphological taxonomy, for example, or sequence alignment — to single-handedly apply today's sophisticated techniques to define these gaps. Clearly, approaches that employ pooled expertise will be the most productive.

We have not calculated the number of authors per year who were responsible for the species descriptions over time, but we did compare, at random, the years 1900 and 2000, which coincidentally have nearly the same number of described species (192 species in 1900 vs. 193 species in 2000) in our database. For the year 1900, the 192 species were described by only 37 workers, compared to more than 100 workers responsible for naming the 193 species described in 2000. Much of the increase is due to jointly authored species descriptions, of which there was only 1 in the year 1900 vs. more than 90 in 2000. Despite a higher number of authors in 2000 , the two years, a century apart, demonstrate that not much has changed in the raw number of described species. Rather, the comparison highlights that more collaborative work is now needed for today's species descriptions.

Although there is no doubting the important contributions to taxonomy of several major marine expeditions, the descriptions stemming from these expeditions are typically published over a period of many years, such that the impact is not 
apparent in any given year. Thus, the relative impacts of the "Challenger" (18721876), "Siboga" (1898-1900), and second "Galathea" (1950-1952) expeditions, to name a few, are not obvious from our analysis (but see Dworschak, 2005, for comments on the "Siboga" Expedition and its contribution to thalassinidean systematics). Similarly, the voluminous contributions of some noted authorities, such as A. G. Humes' work on copepods, were spread over several years, reducing their impact in any given year.

Our data, based on just under 30,000 species, reflect a rate of approximately 160 new crustacean species discovered (described) per year, based on the slope of the regression line for all crustaceans, which is slightly higher than the actual calculated mean of 108 per year because of the slow start in the late 18th century. Plotting the cumulative number of described species using the year 1850 as a starting point, rather than 1750 , results in a far better fit of the regression line (Rsquared $=0.96$, up from 0.93 ) and a slope of 180 , or 180 new species described per year. But because our database includes only half (slightly less, actually) of the estimated 68,000 described species (Brusca \& Brusca, 2003), it is reasonable to conclude, conservatively, that the actual rate of descriptions of new species is close to twice that number, or approximately 300 species per year. And indeed, a recent search of marine species descriptions focusing only on the years 2002 and 2003 (as opposed to examining rates of descriptions averaged over many years) found more than 400 descriptions of crustaceans per year for those two years alone (Philippe Bouchet, pers. comm.).

A reviewer of an earlier draft of this manuscript noted that the increase in number of species may be in some cases (and in some years) an artifact, an increase in our knowledge of the diversity of groups already collected as opposed to results from new collecting and discovery. This is undoubtedly true, especially concerning molecular studies of museum specimens. But it is also true that most new species of crustaceans described in recent years actually are new discoveries and not the result of "splitting" pre-existing taxa based on collections in hand.

Finally, it is clear that we are nowhere close to the end of our task in documenting the diversity of the planet's crustaceans. Improved methods (both in the realm of information technology and in molecular and morphological systematic techniques) are wonderfully helpful. Yet we still desperately need higher numbers of organismically-trained taxonomists and systematists. The work that lies ahead is both daunting and exciting.

\section{ACKNOWLEDGMENTS}

The idea for examining and plotting species descriptions over time based on taxonomic databases is credited to Dr. Gary Rosenberg, Academy of Natural 
Sciences, Philadelphia, who shared with the senior author, during a Census of Marine Life workshop on archiving specimens, his similar graphs based on several mollusk databases. We thank Philippe Bouchet, Laboratoire de Biologie des Invertébrés Marins et Malacologie, Muséum National d'Histoire Naturelle (Paris), for sharing his findings on recent descriptions of marine invertebrates, and Nicholas Gotelli (University of Vermont), Gareth James (University of Southern California), and Paul Martin (Oak Park High School) for statistical advice and suggestions. We sincerely thank Fred Schram and Jeff Shields for providing helpful comments and suggestions on the manuscript, and J. Carel von Vaupel Klein for his editorial expertise and help. This work was funded in part by a grant to J. W. Martin (DEB-EF-0531616) from the National Science Foundation's "Assembling the Tree of Life" program in conjunction with collaborative NSF grants to K. Crandall, D. Felder, R. Feldmann, and C. Schweitzer to investigate the phylogeny of decapod crustaceans. Rafael Lemaitre (U.S. National Museum of Natural History, Washington, D.C.) is gratefully acknowledged for hosting the inaugural meeting of this group in March 2006 where the ideas in this paper were first discussed.

\section{REFERENCES}

Adamowicz, S. J. \& A. Purvis, 2005. How many branchiopod crustacean species are there? Quantifying the components of underestimation. Global Ecology and Biogeography, 14: 455468.

BARNARD, J. L., 1962. Benthic marine Amphipoda of southern California: families Tironidae to Gammaridae. Pacific Naturalist, 3: 73-115.

BILlingS, M., 1997. The influenza pandemic of 1918. On the web at: http://www.stanford.edu/ group/virus/uda/.

BOUCHET, P., 1997. Inventorying the molluscan diversity of the world: what is our rate of progress? The Veliger, 40: 1-11.

BRTEK, J., 1997. Checklist of the valid and invalid names of the "large branchiopods" (Anostraca, Notostraca, Spinicaudata \& Laevicaudata), with a survey of the taxonomy of all Branchiopoda. Zborník Slovenského Národného Múzea (Prírondné Vedy), 43: 1-66.

BruscA, R. C. \& G. J. BrusCA, 2003. Invertebrates (2 ${ }^{\text {nd }}$ ed.): 1-936. (Sinauer Associates, Inc. Sunderland, Massachusetts).

Claus, C., 1863a. Untersuchungen, etc. Recherches sur l'organisation et les affinités des Copépodes. Würzburger Naturwissenschaftliche Zeitschrift [Verh. phys.-mat. Ges. Würzburg], 3: 51-103. [For the year 1862.]

—, 1863b. Die frei lebenden Copepoden mit besonderer Berücksichtigung der Fauna Deutschlands, der Nordsee und des Mittelmeeres: 1-230, pls. 1-37. (Verlag Wilhelm Engelmann, Leipzig).

Crosby, A., 1989. America's forgotten pandemic: the influenza of 1918: 1-69. (Cambridge University Press, Cambridge).

DadAY, E., 1910. Monographie systématique des Phyllopodes Anostracés. Annales des Sciences Naturelles, (Zoologie) (9) 9: 91-489. 
— _, 1913a. Magyarorszag kagylos levellabu rakja (Phyllopoda, Conchostraca). Magyar tudomanyos akademia Matematikai természettudomanyi osztalyanak kozlemenyei, Budaapest, 32: 49-145.

— - 1913b. Deux aberrations intérressantes dans le sous-ordre Phyllopoda Conchostraca. Annales des Sciences Naturelles, (Zoologie) (9) 17: 195-206.

— —, 1913c. Phyllopoda. In: A. Schultz (ed.), Voyage de Ch. Alluaud \& R. Jeannel en Afrique orientale (1911-1912), Résultats scientifiques, Crustacea, 1: 1-9.

— - 1914. Monographie systématique des Phyllopodes Conchostracés. Annales des Sciences Naturelles, (Zoologie) (10) 20: 39-330.

DANA, J. D., 1849. Conspectus crustaceorum, quae in orbis terrarum circumnavigatione, Carolo Wilkes, e classe Reipublicae foederatae duce, lexit et descripsit Jacobus D. Dana. Pars II. Proceedings of the American Academy of Arts and Sciences, 2: 9-61.

- - 1852. Crustacea, Part 1. In: United States Exploring Expedition during the years 1838, 1839 1840, 1841, 1842 under the command of Charles Wilkes, U.S.N., 13: 1-685. (Philadelphia).

DARWIN, C., 1854. A monograph on the subclass Cirripedia with figures of all species. The Balanidae, the Verrucidae, etc.: 1-684. (Ray Society, London).

DE GRAVE, S., 2003. Historical patterns in the description of North East Atlantic Decapoda. Journal of Crustacean Biology, 23(3): 669-677.

DiAmond, J. M., 1985. How many unknown species are yet to be discovered? Nature, London, 315: $538-539$.

DWorschaK, P. C., 2000. Global diversity in the Thalassinidea (Decapoda). Journal of Crustacean Biology, 20 (special number 2): 238-245

— - , 2005. Global diversity in the Thalassinidea (Decapoda): an update (1998-2004). Nauplius, 13(1): 57-63.

Glassell, S. A., 1935. New or little known crabs from the Pacific coast of northern Mexico. Transactions of the San Diego Society of Natural History, 8: 91-106.

— - 1938. New and obscure decapod crustaceans from the west American coasts. Transactions of the San Diego Society of Natural History, 8: 411-454

HaAn, W. DE, 1833-1850. Crustacea. In: P. F. Von Siebold, Fauna Japonica sive Descriptio Animalium, Quae in Itinere per Japoniam, Jussu et Auspiciis Superiorum, qui Summum in India Batava Imperium Tenent, Suscepto. Annis 1823-1830 Collegit Notis, Observationibus et Adumbrationibus Illustravit: (1-243, pls. a-j, 1-q, 1-55). (Lugduni-Batavorum [Leiden]).

Holthuis, L. B., 1991. Marine lobsters of the world. An annotated and illustrated catalogue of species of interest to fisheries known to date. FAO Fisheries Synopsis, 125(13): 1-292, figs. $1-459$

Horgan, J., 1996. The end of science: facing the limits of science in the twilight of the scientific age. (Broadway Books, New York).

Johanson, K. A., 1995. A catalog of the Helicopsychidae (Insecta: Trichoptera) of the world. Bulletin of the Zoölogisch Museum, Amsterdam, 14: 101-123.

Kensley, B., 1998. Estimates of species diversity of free-living isopod crustaceans on coral reefs. Coral Reefs, 17: 83-88.

Kensley, B. \& M. Schotte, 1989. Guide to the marine isopod crustaceans of the Caribbean. (Smithsonian Institution Press, Washington, D.C.).

Köhler, J., D. R. Vieites, R. M. Bonett, F. H. García, F. Glaw, D. Steinke \& M. VINCES, 2005. New amphibians and global conservation: a boost in species discovery in a highly endangered vertebrate group. BioScience, 55(8): 693-696.

KrøYeR, H., 1863. Bidrag til Kundskab om Snyltekrebsene. Naturhistorisk Tidsskrift, (3) 2: 75 426, pls. 1-18.

LAND, M. F., 1996. Les yeux: structure et fonctionnement des mécanismes optiques. In: J. FOREST (ed.), Traité de Zoologie. Anatomie, Systématique, Biologie. Crustacés, Généralités (suite) et Systématique, 7(2): 1-42. (Masson, Paris). 
LANG, K., 1965. Copepoda Harpacticoida from the Californian Pacific coast. Kungliga Svenska Vetenskaps-Akademiens Handlingar, (4) 10(2): 1-560, figs. 1-303, pls. 1-6.

Martin, J. W., 1992. Branchiopoda. In: A. G. Humes \& F. HARRISOn (eds.), Microscopic anatomy of invertebrates, 9, Crustacea: 25-224. (Wiley-Liss Publishers, Inc., New York).

Martin, J. W. \& G. E. DaVis, 2001. An updated classification of the Recent Crustacea. Natural History Museum of Los Angeles County, Science Series, 39: 1-124.

MAY, R. M., 1988. How many species are there on earth? Science, New York, 241: 1441-1449.

- - , 1990. How many species? Philosophical Transactions of the Royal Society of London, (B) 330: $171-182$.

Mclaughlin, P. A., D. K. Camp, M. Angel, E. L. Bousfield, P. Brunel, R. C. Brusca, D. Cadien, A. C. Cohen, K. Conlan, L. G. Eldredge, D. L. Felder, J. W. Goy, T. A. Haney, B. Hann, R. W. Heard, E. A. Hendrycks, H. H. Hobbs, III, J. Holsinger, B. Kensley, D. R. Laubitz, S. E. LeCroy, R. Lemaitre, R. F. Maddocks, J. W. Martin, P. Mikkelsen, E. Nelson, W. A. Newman, R. M. Overstreet, W. J. Poly, W. W. Price, J. W. Reid, A. Robertson, D. C. Rogers, A. Ross, M. Schotte, F. R. Schram, C.-T. Shih, L. Watling, G. D. F. Wilson \& D. D. Turgeon, 2005. Common and scientific names of aquatic invertebrates from the United States and Canada: Crustaceans. American Fisheries Society, (Special Publication) 31: 1-545.

MenZIES, R. J., 1962a. The marine isopod fauna of Bahia de San Quintin, Baja California, Mexico. Pacific Naturalist, 3(11): 337-348.

— - 1962b. The zoogeography, ecology, and systematics of the Chilean marine isopods. Reports of the Lund University Chile Expedition 1948-49, 42. Lund Universitets Årsskrift, (n.s.) (2) 57: $1-62$.

Milne-Edwards, A., 1872. Recherches sur la faune carcinologique de la Nouvelle-Calédonie. Nouvelles Archives du Muséum d'Histoire Naturelle, 8: 229-267, pls. 10-14.

— —, 1880a. Études sur les Xiphosures et les Crustacés podophthalmaires, 7. In: Mission Scientifique au Mexique et dans l'Amérique Centrale, (Recherches zoologiques) 5: 265-312, pls. 31A, 44, 49-54.

— —, 1880b. Études sur les Xiphosures et les Crustacés podophthalmaires, 8. In: Mission Scientifique au Mexique et dans l'Amérique Centrale, (Recherches zoologiques) 5: 313-368 +8 pp. (unnumbered), pls. 55-61.

- $-1880 \mathrm{c}$. Reports on the results of dredging under the supervision of Alexander Agassiz, in the Gulf of Mexico, and in the Caribbean Sea, 1877, '78, '79, by the U. S. Coast Survey Steamer "Blake," Lieut.-Commander C. D. Sigsbee, U. S. N., and Commander J. R. Bartlett, U. S. N., commanding. VIII. Études préliminaires sur les Crustacés, par M. Alph. Milne-Edwards, 1ère partie. Bulletin of the Museum of Comparative Zoology at Harvard, 8(1): 1-68, pls. 1, 2.

Milne EdWARDS, H., 1834-37. Histoire naturelle des Crustacés, comprenant l'anatomie, la physiologie et la classification des ces animaux, 1: 1-532. (Roret, Paris).

Monod, TH. \& L. LAubier, 1996. Les Crustacés dans la biosphère. In: J. Forest (ed.), Traité de Zoologie. Anatomie, Systématique, Biologie. Crustacés, Généralités (suite) et Systématique, 7(2): 91-166. (Masson, Paris).

MÜLlER, H.-G., 1994. World catalog and bibliography of the Recent Stomatopoda. (Wissenschaflicher Verlag, Wetzlar).

Pilsbry, H. A., 1916. The sessile barnacles (Cirripedia) contained in the collections of the U. S. National Museum: including a monograph of the American species. U. S. National Museum Bulletin, 93: 241-353.

Poore, G. C. B., 2004. Marine decapod Crustacea of southern Australia: a guide to identification: 1-616. (CSIRO Publishing, Australia). [With S. T. AHYONG.]

Rathbun, M. J., 1906. The Brachyura and Macrura of the Hawaiian Islands. U. S. Fisheries Commission Bulletin, 3: 827-930, pls. 1-24. 
— —, 1925. The spider crabs of America. United States National Museum Bulletin, 129: i-x, 1-613, pls. 1-283.

— - 1930. The cancroid crabs of America of the families Euryalidae, Portunidae, Atelecyclidae, Cancridae, and Xanthidae. United States National Museum Bulletin, 152: 1-609, pls. 1-230.

— - 1933. Brachyuran crabs of Porto Rico and the Virgin Islands. In: Scientific Survey of Porto Rico and the Virgin Islands, 15(1): 1-121, 107 text-figs. (New York Academy of Sciences).

- - , 1937. The oxystomatous and allied crabs of America. United States National Museum Bulletin, 166: 1-278, pls. 1-86.

SARS, G. O., 1862a. Hr. Studios med. G. O. Sars medeelte en af talrige Afbildninger ledsaget Oversigt af de af ham i Omegnen af Christiania iagttagne Crustacea Clacodera. Forhandlinger i Videnskabs-Selskabet i Christiania, 1861: 144-167.

— —, 1862b. Hr. Studios med. G. O. Sars fortsatte sit Foregrad over de af ham i Omegnen af Christiana iagttagne Crustacea Clacodera. Forhandlinger i Videnskabs-Selskabet i Christiania, 1861: $250-302$.

— - 1863. Beretning om en i Sommeren 1863 foretagen zoologisk Reise i Christiania og Trondhjems Stifter. Nyt Magazin for Naturvidenskaberne, 12: 193-252.

— - 1901. Contributions to the knowledge of the fresh-water Entomostraca of South America, as shown by artificial hatching from dried material. Part 1. Cladocera. Arch. Math. Naturvidensk., 23: $1-101$.

Schmitt, W. L., 1935. Crustacea Macrura and Anomura of Porto Rico and the Virgin Islands. Scientific Survey of Puerto Rico and the Virgin Islands, 159(2): 125-227.

SCHRAM, F. R., 2003. Our evolving understanding of biodiversity through history and its impact on the recognition of higher taxa in Metazoa. In: A. LEGAKIS et al. (eds.), The new panorama of animal evolution, Proc. XVIIIth Int. Congr. Zool.: 359-368. (Pensoft Publ., Sofia).

SChraM, F. R. \& H.-G. MÜLler, 2004. Catalog and bibliography of the Recent and fossil Stomatopoda. (Backhuys Publications, Leiden).

Stimpson, W., 1860. Notes on North American Crustacea, in the museum of the Smithsonian Institution. No. II. Annals of the Lyceum of Natural History of New York, 7: 176-246, pls. 2, 3.

_ - 1871a. Notes on North American Crustacea, in the museum of the Smithsonian Institution, III. Annals, Lyceum of the Natural History of New York, 10: 92-136.

_ -1871 b. Preliminary report on the Crustacea dredged in the Gulf Stream in the Straits of Florida by L.F. de Pourtalès, assistant United States Coast Survey. Part I. Brachyura. Bulletin of the Museum of Comparative Zoology at Harvard College, 2(2): 109-160.

STORK, N. E., 1993. How many species are there? Biodiversity and Conservation, 2: 215-232.

WiLliams, A. B., 1984. Shrimps, lobsters, and crabs of the Atlantic coast of the United States, Maine to Florida: i-xviii, 1-550. (Smithsonian Institution Press, Washington, D.C.).

Wilson, E. O., 2003. The encyclopaedia of life. Trends in Ecology and Evolution, 18: 77-80.

Wittmann, K. J., 1999. Global biodiversity in the Mysidacea, with notes on the effects of human impact. In: F. R. SCHRAM \& J. C. VON VAUPEL KLEIN (eds.), Crustaceans and the biodiversity crisis. Proceedings of the Fourth International Crustacean Congress, Amsterdam, The Netherlands, July 20-24, 1998, 1: 511-525. (Brill, Leiden).

First received 11 April 2006.

Final version accepted 18 July 2006. 